\title{
Segmentasi Citra Bunga Menggunakan Blob Analisis
}

\author{
Ines Hediani Ikasari, Resti Amalia, Perani Rosyani* \\ Fakultas Teknik, Program Studi Teknik Informatika, Universitas Pamulang, Tangerang Selatan, Indonesia \\ Email: 1'dosen01374@unpam.ac.id, ${ }^{2}$ dosen00850@unpam.ac.id, ${ }^{3,}{ }^{*}$ dosen00837@unpam.ac.id \\ Email Penulis Korespondensi: dosen00837@unpam.ac.id \\ Submitted: 18/12/2021; Accepted: 26/12/2021; Published: 31/12/2021
}

\begin{abstract}
Abstrak-Content Based Image Retrieval (CBIR) untuk segmentasi citra sedang menjadi perhatian tahun ini khususnya didalam perkembangan computer vision. Objek yang di bahas didalam penelitian ini adalah mengenai bunga, di mana menggunakan dataset dari ImageCLEF2017 dengan mengambil 8 sample bunga. Citra bunga yang ada didalam dataset tersebut masih banyak noise seperti background awal di belakang objek seperti daun, batang pohon atau yang lainnya. Sehingga diperlukan metode untuk menghilangkan noise tersebut, metode untuk membersihkan noise ini dilakukan dengan mengkluster warna menggunakan metode K-means. Dengan mengkluster warna menggunakan K-Means dan menggunakan kluster warna k=2,3,4, dan 5. Setelah itu dilakukan proses morphologi agar didapat area yang bersih sehingga dapat dibandingkan dengan citra asal dan di itung nilai Blob yang terbentuk. Blob analisis di hitung setelah proses pembersihan noise dilakukan dengan tujuan untuk mendapatkan nilai terbaik didalam proses pengenalan citra dengan objek bunga. Hasil dari proses segmentasi yang telah di lakukan nilai MSE dan RMSE tertinggi berada pada hasil $\mathrm{k}$-means dengan $\mathrm{k}=4$, sedangkan untuk PNSR berada pada $\mathrm{k}=2$, dan untuk nilai MSE dan RMSE terendah ada pada $\mathrm{k}=5$, sedangkan PNSR tersendah ada pada $\mathrm{k}=4$.
\end{abstract}

Kata Kunci: Computer Vision, Bunga, CBIR, Blob Analisis

\begin{abstract}
Content Based Image Retrieval (CBIR) for image segmentation is a concern this year, especially in the development of computer vision. The object discussed in this study is about interest, which uses a dataset from ImageCLEF2017 by taking 8 flower samples. Image of flowers in the dataset is still a lot of noise such as the initial background behind objects such as leaves, tree trunks or others. So we need a method to eliminate the noise, this method for cleaning noise is done by color clusters using the Kmeans method. By color clustering using $\mathrm{K}-\mathrm{Means}$ and using color clusters $\mathrm{k}=2,3,4$,and5. After that, a morphological process is carried out in order to obtain a clean area so that it can be compared with the original image and the Blob values formed. Blob analysis is calculated after the process of cleaning the noise is done in order to get the best value in the process of recognition of images with objects of interest. The results of the segmentation process that have been done are the highest MSE and RMSE values are at $\mathrm{k}$-means results with $\mathrm{k}=4$, while for PNSR are at $\mathrm{k}=2$, and for the lowest MSE and RMSE values are at $\mathrm{k}=5$, while the lowest PNSR is at $\mathrm{k}=4$.
\end{abstract}

Keywords: Computer Vision; Flower; CBIR; Blob Analisys

\section{PENDAHULUAN}

Segmentasi gambar merupakan langkah penting dalam pemprosesan sebuah gambar, serta penting didalam computer vision[1]. Segmentasi merupakan proses pengambilan karakteristik sebuah gambar dari suatu objek. Karateristik ini bisa berupa nilai setiap elemen warna, luas atau keliling area yang terbentuk, tekstur yang dihasilkan,dll. Kualitas dari segmentasi gambar secara langsung mempengaruhi penglahan citra ini merupakan masalah didalam banyak penelitian [2]. Begitu banyak algoritma yang diterapkan dalam proses segmentasi untuk mendapatkan hasil segmentasi terbaik misalnya dengan metode global threshold[3], otsu threshold[4], pencarian entropy[5], grabcut[6] dan lain-lain.

Tujuan segmentasi ini untuk mencari sejumlah area yang tidak terpotong dan daerah yang memiliki sifat-sifat berdekatan dengan perbedaan yang jelas proses segmentasi sangat penting bagi didalam penelitian computer vision. Selain itu juga dapat untuk mengenali sebuah objek [7] atau mendeteksi jumlah objek yang ada[8][9].

Dalam penelitian ini kami mengambil 8 citra Bunga dari dataset ImageClef2017. Citra bunga ini kami segmentasi menggunakan metode $\mathrm{K}$-means untuk dengan kluster warna $\mathrm{K}=2,3,4,5$ pada hal ini melihat penelitian [10]yang sebelumnya menggunakan kluster warna hingga $\mathrm{k}=10$. Kami mengambil fitur warna RGB dan dikonvert menjadi warna $\mathrm{LAB}$, karena fitur warna $\mathrm{LAB}$ sangat baik digunakan untuk segmentasi didalam metode K-means [11]. Warna LAB juga sangat sesuai untuk menganalisa statistik warna untuk ekstraksi fitur warna yang lebih baik dan mereduksi jumlah perhitungan pixel[12]. Penggunaan metode mophologi seperti holes[13] dan filter untuk menghapus noise merupakan operator morphologi untuk meningkatkan hasil segmentasi yang sudah dilalui melalui k-means. Kemudian kami menggunakan blob analisa untuk menganalisa area yang terbentuk dari hasil segmentasi menggunakan K-means. Blob terbentuk berdasarkan wilayah yang lebih terang dari keadaan sekitar area citra.[14].

Dari nilai blob yang terbentuk kami akan membandingkan jumlah blob dengan groundtruth yang ada. GroundTruth ini untuk menentukan kualitas hasil dari area segmentasi[15] yang terbentuk. GroundTruth ini didapat dengan menghilangkan background gambar yang ada menggunakan aplikasi photoshop. Hal ini agar didapat hasil GroundTruth yang lebih baik pada saat dibandingkan dengan hasil gambar setelah segmentasi. Hal ini menentukan tingkat akurasi yang baik dalam menilai hasil segmentasi tersebut. Hasil akhir untuk menentukan akurasi terbaik dari hasil kluster k=2,3,4 dan5 menggunakan Mean Square Error (MSE), Root Mean Square Error (RMSE), dan Peak Signal to Noise Ratio (PSNR) untuk setiap kluster segmentasi 


\section{METODOLOGI PENELITIAN}

Berikut adalah metode penelitian yang diusulkan di mulai dari pemilihan dataset hingga perhitungan blob Analisa. Berikut adalah langkah-langkah dari alur penelitian yang kami kerjakan.

1. Mulai adalah dimana tahap awal dalam penelitian ini dengan mendownload datasets.

2. Pemilihan sample adalah memilih model bunga yang ingin di jadikan bahan penelitian. Dalam tahapan ini kami memilih 8 sample bunga dengan warna yang berbeda-beda. Didalam tahapan ini juga sample akan di olah selanjutnya. Sample ini menggunakan data set dari ImageClef2017.

3. Pembuatan ground Truth merupakan pencarian hasil segmentasi citra terbaik yang didapat hasil dari segmentasi manual dan segmentasi menggunakan meted K-means dan manual sehingga terbentuk area utuh dari bunga tersebut. GroundTruth ini nantinya yang akan di bandingkan hasilnya dengan hasil segmentasi dari kluster warna $\mathrm{K}=2,3,4,5$. Pembuatan groundTruth ini menggunakan photoshop agar objek awal lebih baik hasilnya jika dibandingkan dengan hasil segmentasi.

4. Pengambilan segmentasi GroundTruth didapat dari hasil segmentasi menggunakan metode atau dengan proses penambahan manual.

5. Proses k-means k2,3,4 dan 5 adalah memproses sample gambar dengan kluster warna tersebut. Didalam proses kluster ini ada tahapan morphologi seperti holes, filter dan open area untuk pembersihan sekitar gambar

6. Pengambilan segmentasi GT dan Kmeans ini adalah proses yang sama di mana kita mengambil nilai boundary berdasarkan hasil segmentasi yang terbentuk dari beberapa kluster tersebut.

7. Analisa blob merupakan pencarian nilai daerah yang terbentuk dari hasil segmentasi, blob yang dihitung adalah area dan keliling area yang terbentuk

8. Nilai MSE, RMSE dan PSNR untuk menghitung tingkat terbaik hasil segmentasi warna dengan $\mathrm{K}=2,3,4$ dan 5

$$
\begin{aligned}
& M S E=\frac{1}{m x n} \sum_{i=0}^{n-1} \sum_{j=0}^{m-1}[f(i, j)-g(i, j)]^{2} \\
& R M S E=\sqrt{\frac{1}{m x n} \sum_{i=0}^{n-1} \sum_{j=0}^{m-1}[f(i, j)-g(i, j)]^{2}} \\
& P N S R=10 \log _{10} \frac{255^{2}}{M S E}
\end{aligned}
$$

Berikut gambaran dari penjelasan paparan di atas mengenai tahapan penelitian didalam penelitian yang dilakukan.

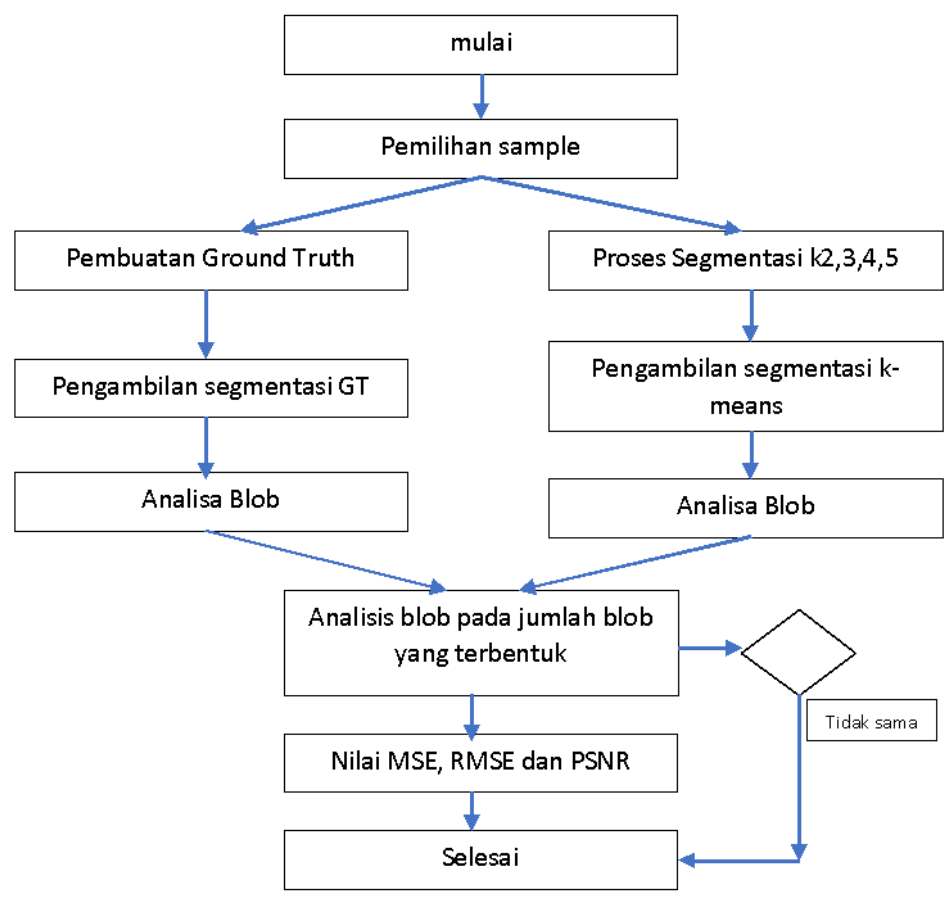

Gambar 1. Tahapan Penelitian 


\subsection{Metode Pengumpulan Data}

a. Studi Pustaka

Penulisan ini dilakukan melalui media pustaka, yaitu media internet dan media buku, membaca buku referensi yang berkaitan dengan Content Based Image Retrieval. Karena dalam membuat proses pengenalan objek, diperlukan referensi - referensi yang mendukung penulis untuk membuat aplikasi ini. Media internet untuk melihat contoh - contoh yang sudah ada, sehingga penulis bisa mendapatkan gambaran dari proses pengenalan wajah. Aplikasi yang digunakan untuk segmentasi image ini adalah Matlab

b. Pemilihan dataset dari ImageClef 2017

Pemilihan dataset ini dilakukan manual dengan memilih bunga tunggal agar bisa di ekstrak sehingga mendapatkan hasil segmentasi yang diinginkan. Bunga yang terpilih adalah calochortus invenustus Greene, Calochortus Venustus Douglas ex Benth, Calochortus Luteus Douglas ex Lindl, Calochortus Kennedy Porter, Calochortus venustus Douglas ex Benth, Rosa Canin L, Rosa Chinensis Jacq, *.Rosa Rugosa Thunb

\section{HASIL DAN PEMBAHASAN}

Didalam pembahasan ini adalah membahas proses dari alur penelitian yang kami sajikan dengan gambar-gambar hasil segmentasi.

\section{a. Datasets}
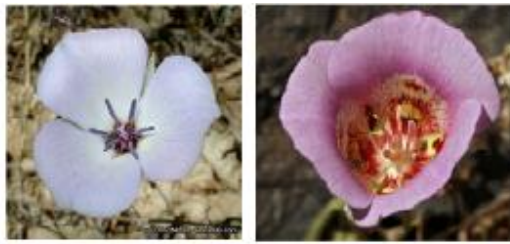

1. Calochortus
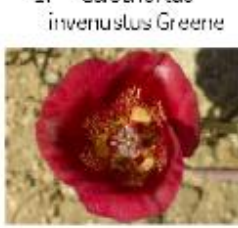

5. Lalochortus venustus vouzlas ex Benth
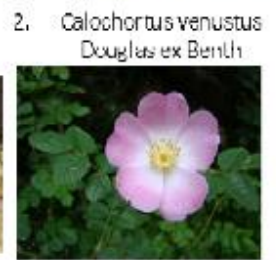

b. Hosacanina L
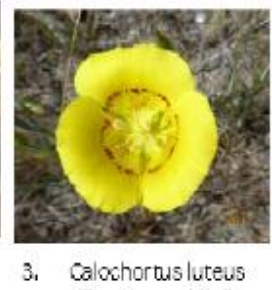
Dustas ex Linul

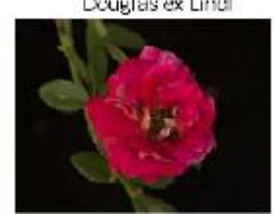

1. Rosa chinensis Jaco

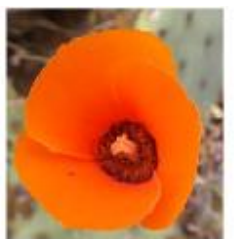

4. Calochortus kenmediyi Pux les

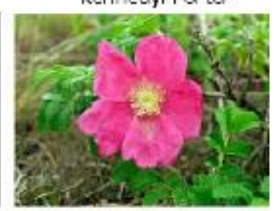

๖. kosa rugosa Ihunb

Gambar 2. Dataset

Keterangan Gambar:

1.calochortus invenustus Greene, 2. Calochortus Venustus Douglas ex Benth, 3. Calochortus Luteus Douglas ex Lindl, 4. Calochortus Kennedy Porter, 5.Calochortus venustus Douglas ex Benth, 6.Rosa Canin L, 7.Rosa Chinensis Jacq, *.Rosa Rugosa Thunb

Gambar 2 merupakan dataset yang dipilih dikonvert menjadi warna LAB yang kemudian baru diproses segmentasi menggunakan K-means dengan kluster warna $\mathrm{k}=2,3,4$ dan 5 serta pembuatan groundTruth. Setelah proses K-means dilakukan proses morphologi seperti holes, filter dan openarea untuk menghilangkan noise di sekitarnya.

\section{b. Hasil Segmentasi dan Operasi morphologi}

Tabel 1. Hasil proses Segmentasi dari GroundTruth hingga pengklasteran warna $\mathrm{K}=2,3,4$ dan 5

\begin{tabular}{|c|c|c|c|c|}
\hline Citra Asli & $\mathrm{K} 2$ & $\mathrm{~K} 3$ \\
\hline & $\mathrm{K} 4$ & $\mathrm{~K}$ \\
\hline
\end{tabular}


Building of Informatics, Technology and Science (BITS)

Volume 3, No 3, December 2021, Page 228-234

ISSN 2684-8910 (media cetak)

ISSN 2685-3310 (media online)

DOI 10.47065/bits.v3i3.1050

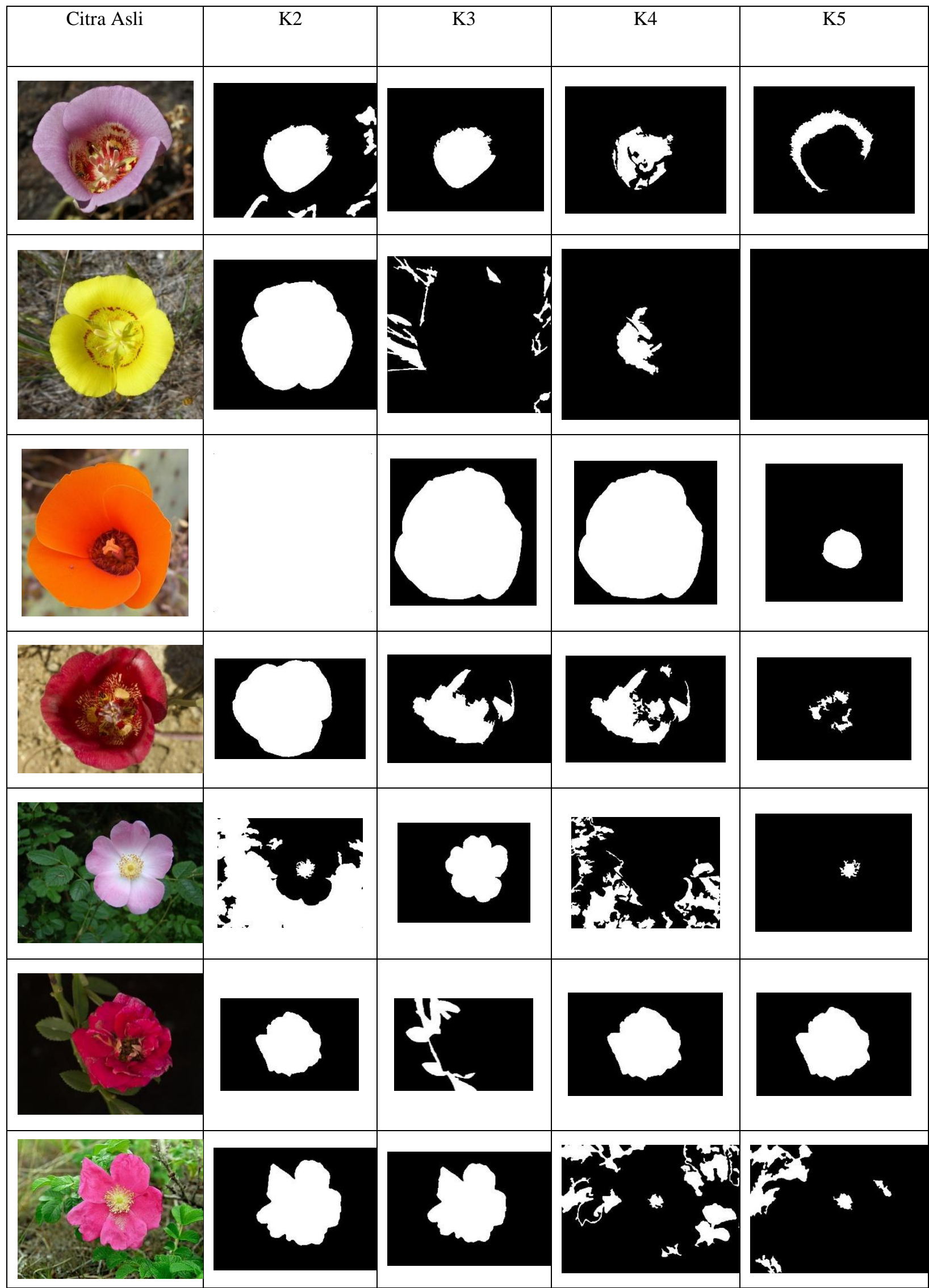

Dari tabel diatas bisa kita lihat hasil segmentasi dengan kluster $\mathrm{K}=2,3,4$ dan 5 , ada beberapa hasil segmentasi yang nilainya 0 artinya hasil segementasi hasilnya tidak terlihat. 
Building of Informatics, Technology and Science (BITS)

Volume 3, No 3, December 2021, Page 228-234

ISSN 2684-8910 (media cetak)

ISSN 2685-3310 (media online)

DOI 10.47065/bits.v3i3.1050

\section{c. Analisa Blob}

Dari hasil segmentasi ini kita akan Analisa nilai blob yang terbentuk dari masing-masing gambar. Setiap blob mempunyai jumlah blob yang berbeda setelah hasil segmentasi, hal ini dapat terlihat dari tabel dibawah ini.

Tabel 2. tabel hasil proses blob

\begin{tabular}{|c|c|c|c|c|c|c|c|c|c|c|c|}
\hline \multirow{2}{*}{ Nama Bunga } & \multirow{2}{*}{$\begin{array}{l}\text { jumlah } \\
\text { blob }\end{array}$} & \multicolumn{2}{|c|}{ GT } & \multicolumn{2}{|c|}{ K2 } & \multicolumn{2}{|c|}{ K3 } & \multicolumn{2}{|c|}{ K4 } & \multicolumn{2}{|r|}{ K5 } \\
\hline & & Area & Perimeter & Area & Perimeter & Area & Perimeter & Area & Perimeter & Area & Perimeter \\
\hline & & 13751 & & 14187 & & & & & & & \\
\hline Calochortus & 1 & 5 & 1887.4 & 7 & 1915.3 & 1567 & 356.8 & 1440 & 511.1 & 1191 & 445.8 \\
\hline invenustus & 2 & & & 1098 & 225.6 & 1320 & 490.2 & 19382 & 1187.4 & 20028 & 1219 \\
\hline Greene & 3 & & & & & 1805 & 335.9 & 6938 & 509.9 & 7015 & 508 \\
\hline & 4 & & & & & 6488 & 465.9 & 1198 & 225.9 & & \\
\hline & 5 & & & & & 16799 & 1158.2 & & & & \\
\hline & 6 & & & & & 1125 & 210.7 & & & & \\
\hline & 7 & & & & & 2960 & 375.2 & & & & \\
\hline & 8 & & & & & 1051 & 180.2 & & & & \\
\hline & 9 & & & & & 1189 & 509.7 & & & & \\
\hline & 10 & & & & & 1421 & 240 & & & & \\
\hline & 11 & & & & & 1203 & 195.1 & & & & \\
\hline Calochortus & & 13566 & & & & & & & & & \\
\hline venustus & 1 & 2 & 1432.5 & 2133 & 259.3 & 39147 & 891.9 & 24965 & 1555.5 & 22942 & 1630.3 \\
\hline Douglas ex & 2 & & & 40380 & 850 & & & 1052 & 196.8 & & \\
\hline Benth & 3 & & & 1913 & 303.2 & & & 2177 & 242.1 & & \\
\hline & 4 & & & 1941 & 224.7 & & & & & & \\
\hline & 5 & & & 3550 & 353.6 & & & & & & \\
\hline & 6 & & & 2963 & 380.3 & & & & & & \\
\hline & 7 & & & 1394 & 238.8 & & & & & & \\
\hline & & 10448 & & 10712 & & & & & & & \\
\hline & 1 & 5 & 1264.6 & 1 & 1252.5 & 1503 & 198.5 & 12589 & 1011.6 & & \\
\hline & 2 & & & & & 1405 & 383.1 & & & & \\
\hline & 3 & & & & & 5654 & 625.9 & & & & \\
\hline Calochortus & 4 & & & & & 3841 & 973.1 & & & & \\
\hline luteus Douglas & 5 & & & & & 1061 & 161.9 & & & & \\
\hline ex Lindl & 6 & & & & & 1084 & 332.1 & & & & \\
\hline & 7 & & & & & 4154 & 908.9 & & & & \\
\hline & 8 & & & & & 1096 & 233.2 & & & & \\
\hline & 9 & & & & & 2091 & 437.8 & & & & \\
\hline Calochortus & & 21411 & & 36058 & & 21582 & & 21556 & & & \\
\hline kennedyi & 1 & 1 & 1778.8 & 8 & 2344.9 & 1 & 1725 & 1 & 1722.7 & 22135 & 543.4 \\
\hline & & 11209 & & 11320 & & & & & & & \\
\hline Calochortus & 1 & 1 & 1290.8 & 1 & 1253.6 & 41916 & 1373.7 & 33704 & 1636.2 & 2863 & 517.6 \\
\hline venustus & 2 & & & & & 4698 & 494.3 & 3690 & 423.5 & 2188 & 468.9 \\
\hline Douglas ex & 3 & & & & & & & 1035 & 176.2 & 1905 & 316.4 \\
\hline Benth & 4 & & & & & & & 4783 & 514 & & \\
\hline & & & & 14422 & & & & & & & \\
\hline & 1 & 58803 & 1072.9 & 3 & 3228.6 & 60166 & 1044.1 & 1198 & 209.6 & 2783 & 431.2 \\
\hline & 2 & & & 1520 & 245.7 & & & 7516 & 1221.8 & & \\
\hline & 3 & & & 3806 & 447.4 & & & 3385 & 653.6 & & \\
\hline & 4 & & & 1770 & 212.2 & & & 1458 & 215.1 & & \\
\hline & 5 & & & & & & & 20406 & 1696.7 & & \\
\hline & 6 & & & & & & & 1065 & 350.3 & & \\
\hline Rosa canina L & 7 & & & & & & & 2117 & 311.9 & & \\
\hline & 8 & & & & & & & 1562 & 225.7 & & \\
\hline & 9 & & & & & & & 1918 & 240.3 & & \\
\hline & 10 & & & & & & & 1144 & 188.1 & & \\
\hline & 11 & & & & & & & 14028 & 1457.4 & & \\
\hline & 12 & & & & & & & 2683 & 454.9 & & \\
\hline & 13 & & & & & & & 3273 & 345 & & \\
\hline $\begin{array}{c}\text { Rosa chinensis } \\
\text { Jacq }\end{array}$ & 1 & 52896 & 944.5 & 54069 & 923.2 & 31642 & 2044.7 & 54886 & 929 & 55098 & 931.6 \\
\hline Rosa rugosa & 1 & 52383 & 1078.3 & 53711 & 1045.1 & 53203 & 1044.5 & 8652 & 936.5 & 17143 & 1588.8 \\
\hline Thunb & 2 & & & & & & & 8473 & 1269.7 & 1906 & 372.3 \\
\hline & 3 & & & & & & & 1244 & 215.9 & 1766 & 220 \\
\hline & 4 & & & & & & & 1021 & 243.8 & 1027 & 193.2 \\
\hline & 5 & & & & & & & 3745 & 572.1 & & \\
\hline & 6 & & & & & & & 9432 & 660.8 & & \\
\hline & 7 & & & & & & & 1234 & 201.6 & & \\
\hline
\end{tabular}


Building of Informatics, Technology and Science (BITS)

Volume 3, No 3, December 2021, Page 228-234

ISSN 2684-8910 (media cetak)

ISSN 2685-3310 (media online)

DOI 10.47065/bits.v3i3.1050

\begin{tabular}{|c|c|c|c|c|c|c|c|c|c|c|c|}
\hline \multirow{2}{*}{ Nama Bunga } & \multirow{2}{*}{$\begin{array}{c}\text { jumlah } \\
\text { blob }\end{array}$} & \multicolumn{2}{|c|}{ GT } & \multicolumn{2}{|c|}{ K2 } & \multicolumn{2}{|c|}{ K3 } & \multicolumn{2}{|c|}{$\mathrm{K} 4$} & \multicolumn{2}{|r|}{ K5 } \\
\hline & & Area & Perimeter & Area & Perimeter & Area & Perimeter & Area & Perimeter & Area & Perimeter \\
\hline & 8 & & & & & & & 5980 & 681.8 & & \\
\hline & 9 & & & & & & & 1223 & 425.6 & & \\
\hline & 10 & & & & & & & 1499 & 550 & & \\
\hline
\end{tabular}

Dapat dilihat hasil dari tabel 1 , blob yang terbentuk ada yang over bahkan tidak terbentuk sama sekali. Dari Analisa diatas kami mengambil jumlah blob yang sama untuk dianalisa dan diambil kesimpulannya.

\section{d. Jumlah Blob Terbentuk}

Jumlah blob yang terbentuk ini akan di bandingkan dengan jumlah Groundtruth, karena pada penelitian ini kami hanya menggunakan bunga tunggal. Sehingga semua jumlah yang lebih dari 1 objek akan disisihkan atau tidak dihitung untuk meningkatkan nilai akurasinya.

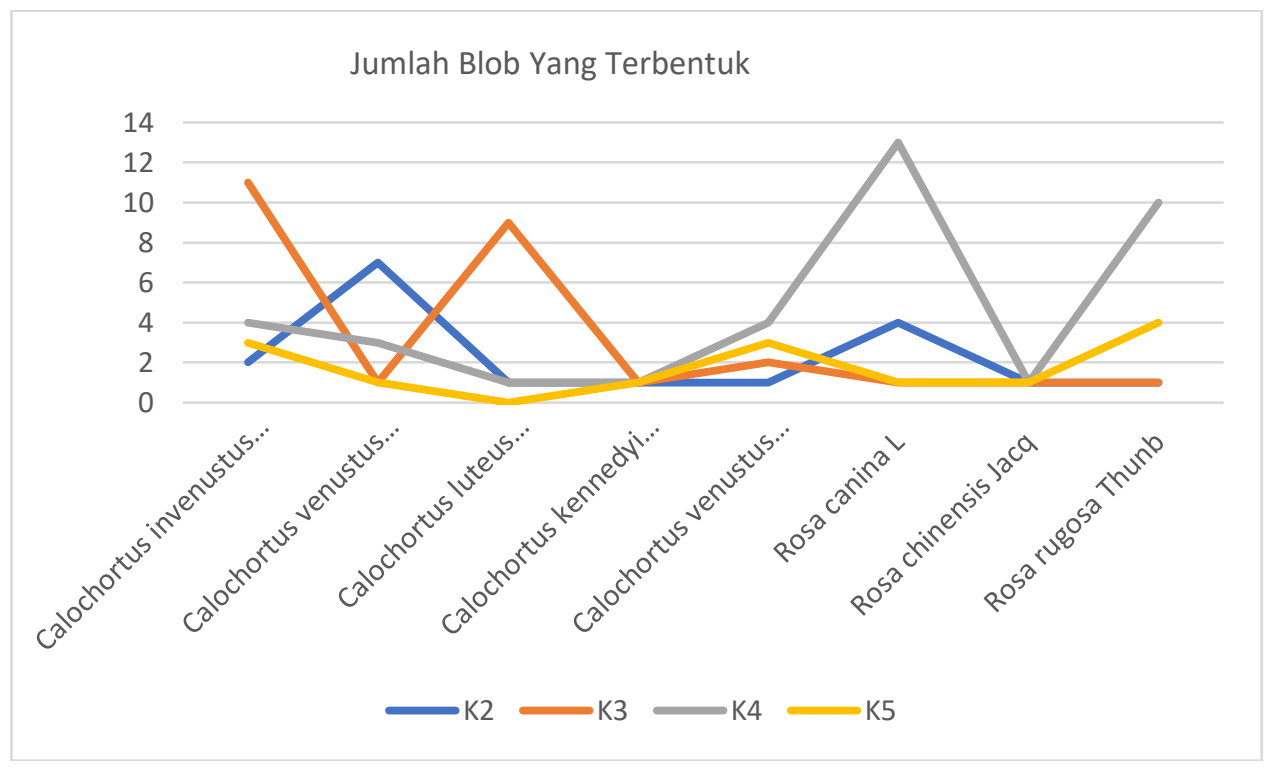

Gambar 3. Jumlah blob yang terbentuk hasil segmentasi dari setiap bunga

Setelah didapat jumlah setiap blobnya kita hitung nilai Mean Square Error (MSE), Root Mean Square Error (MSE), dan Peak Signal to Noise Ratio (PSNR)

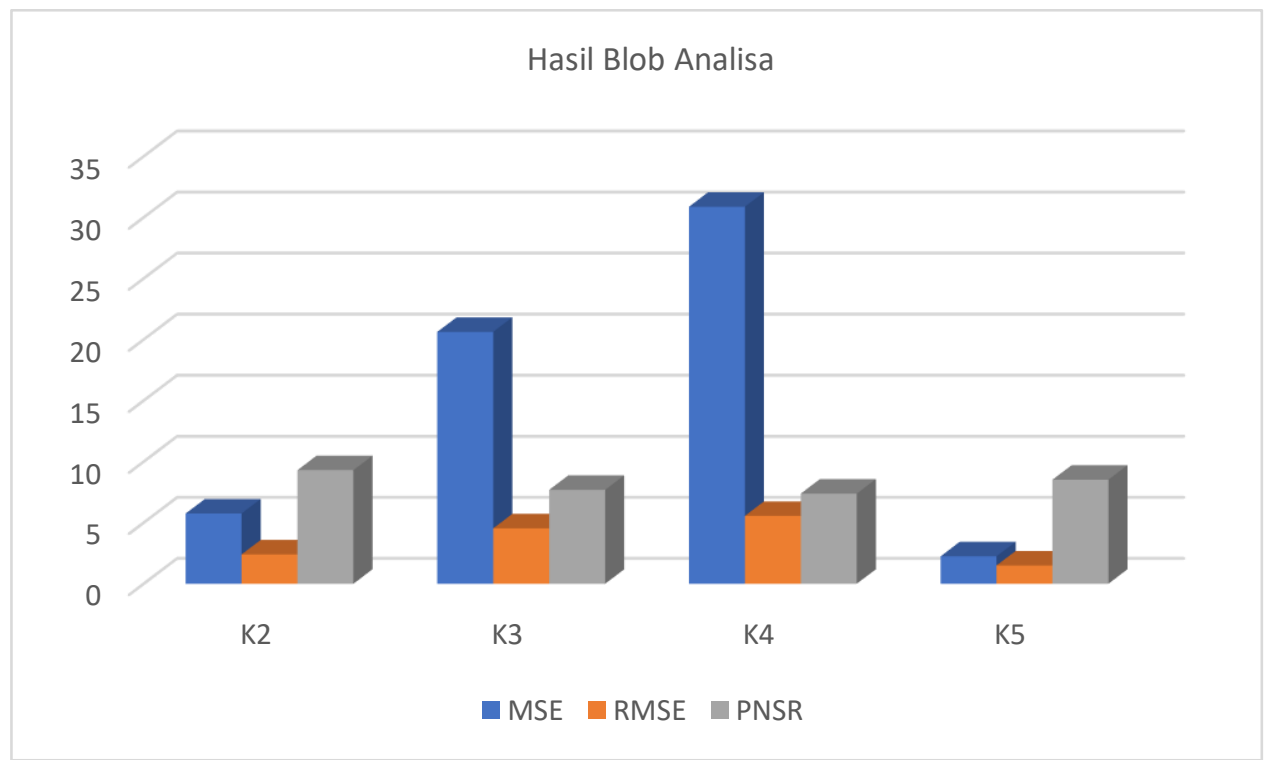

Gambar 4. Hasil Blob Analisa MSE, RMSE, Dan PSNR

Berdasarkan grafik diatas dapat kita lihat nilai MSE dan RMSE tertinggi berada pada hasil k-means dengan $\mathrm{k}=4$, sedangkan untuk PNSR berada pada $\mathrm{k}=2$, dan untuk nilai MSE dan RMSE terendah ada pada $\mathrm{k}=5$, sedangkan PNSR tersendah ada pada $\mathrm{k}=4$. 


\section{KESIMPULAN}

Kesimpulan dari segmentasi citra bunga menggunakan blob analisa yakni berdasarkan hasil perhitungan MSE, RMSE dan PSNR dengan membandingkan nilai blob yang tebentuk diatas maka dapat di katakan hasil terbaik adalah nilai MSE dan RMSE tertinggi berada pada hasil k-means dengan $\mathrm{k}=4$, sedangkan untuk PNSR berada pada $\mathrm{k}=2$. Untuk nilai MSE dan RMSE terendah ada pada $\mathrm{k}=5$, sedangkan PNSR tersendah ada pada $\mathrm{k}=4$.

\section{REFERENCES}

[1] Y. Li, J. Zhang, P. Gao, L. Jiang, and M. Chen, "Grab Cut Image Segmentation Based on Image Region," 2018 IEEE 3rd Int. Conf. Image, Vis. Comput., pp. 311-315, 2018.

[2] K. Jiao and Z. Pan, "A Novel Method for Image Segmentation Based on Simplified Pulse Coupled Neural Network and Gbest Led Gravitational Search Algorithm," IEEE Access, vol. 7, pp. 21310-21330, 2019.

[3] G. B. Adhi and I. D. Wahyono, "Segmentasi Gambar Warna Menggunakan Sauvola Modifikasi Fuzzy C-Means (Smfem)," Lontar Komput., vol. 5, no. 2, pp. 416-423, 2015.

[4] T. Arifin, "Analisa Perbandingan Metode Segmentasi Citra Pada Citra Mammogram," J. Inform., vol. 3, no. 2, pp. 156-163, 2016.

[5] T. X. Pham, P. Siarry, and H. Oulhadj, "Integrating fuzzy entropy clustering with an improved PSO for MRI brain image segmentation," Appl. Soft Comput. J., vol. 65, pp. 230-242, 2018.

[6] W. Tan, T. Sunday, and Y. Tan, "Enhanced "GrabCut' Tool with Blob Analysis in Segmentation of Blooming Flower Images," 2013.

[7] P. Rosyani, "Pengenalan Wajah Menggunakan Metode Principal Component Analysis (PCA) dan Canberra Distance," J. Inform. Univ. Pamulang, vol. 2, no. 2, p. 118, 2017.

[8] J. Lazić, "Image Processing and Computer Vision with MATLAB and SIMULINK," 2015.

[9] N. L. W. S. R. Ginantra, "Deteksi Batik Parang Menggunakan Fitur Co-Occurence Matrix Dan Geometric Moment Invariant Dengan Klasifikasi KNN," Lontar Komput. J. Ilm. Teknol. Inf., vol. 7, no. 1, p. 40, 2016.

[10] Atina, "Segmentasi Citra Paru Menggunakan Metode k-Means Clustering," Segmentasi Citra Paru Menggunakan Metod. $k$ Means Clust., vol. 3, no. 2, pp. 57-65, 2017.

[11] P. Rosyani, M. Taufik, A. A. Waskita, and D. H. Apriyanti, "Comparison of color model for flower recognition," 2018 3rd Int. Conf. Inf. Technol. Inf. Syst. Electr. Eng., pp. 10-14, 2019.

[12] J. Dong, X. Qu, and H. Li, "Color tattoo segmentation based on skin color space and K-mean clustering," ICCSS 2017 - 2017 Int. Conf. Information, Cybern. Comput. Soc. Syst., pp. 53-56, 2017.

[13] D. H. Apriyanti, A. M. Arymurthy, and L. T. Handoko, "Identification of orchid species using content-based flower image retrieval," Proceeding - 2013 Int. Conf. Comput. Control. Informatics Its Appl. "Recent Challenges Comput. Control Informatics", IC3INA 2013, no. March 2015, pp. 53-57, 2013.

[14] K. Thwe and M. Han, “A Survey of Blob Detection Algorithms for Biomedical Images,” vol. 2016, pp. 0-3, 2016.

[15] S. Ait-Aoudia, E. H. Guerrout, and R. Mahiou, "Medical image segmentation using particle swarm optimization," Proc. Int. Conf. Inf. Vis., pp. 287-291, 2014. 